\title{
(2) OPEN ACCESS \\ Wish to die and hasten death in palliative care: a cross-sectional study factor analysis
}

\author{
Alazne Belar (D) ,1,2 Marina Martinez, ${ }^{2,3}$ Carlos Centeno (D) ,1,2 \\ Jesús López-Fidalgo, ${ }^{4}$ Yolanda Santesteban, ${ }^{5}$ Marcos Lama, ${ }^{6}$ \\ Maria Arantzamendi ${ }^{1,2}$
}

- Additional supplemental material is published online only. To view, please visit the journal online (http://dx.doi. org/10.1136/bmjspcare-2021 003080)

${ }^{1}$ Instituto Cultura y Sociedad, Universidad de Navarra, Pamplona, Spain

${ }^{2}$ IdiSNA, Pamplona, Spain

${ }^{3}$ Medicina Paliativa, Clínica

Universidad de Navarra,

Pamplona, Spain

${ }^{4}$ Institute of Data Science and Artificial Intelligence, Universidad de Navarra, Pamplona, Spain ${ }^{5}$ Obra Social LaCaixa, Hospital San Juan de Dios Pamplona, Pamplona, Spain

${ }^{6}$ Servicio Navarro de Salud Osasunbidea, Pamplona, Spain

\section{Correspondence to}

Dr Marina Martinez, Clínica Universidad de Navarra, Pamplona, Navarra 31008, spain; mmargarcia@unav.es

Received 29 March 2021 Accepted 5 August 2021

Check for updates

(C) Author(s) (or their employer(s)) 2021. Re-use permitted under CC BY-NC. No commercial re-use. See rights and permissions. Published by BMJ

To cite: Belar A, Martinez $M$ Centeno C, et al. BMJ

Supportive \& Palliative

Care Epub ahead of

print: [please include Day

Month Year]. doi:10.1136/

bmjspcare-2021-003080

\section{ABSTRACT}

Objectives The wish to die (WTD) is a complex experience sometimes accompanied by intention to hasten death. The aim of this study is to identify the predictive factors for WTD and hastening death intention (HDI) in Spanish patients with advanced illness.

Methods This is a subanalysis of a larger cross-sectional study conducted on patients experiencing advanced illness $(\mathrm{N}=201)$. Sociodemographic data and data related to symptom burden (Edmonton Symptom Assessment System-Revised), depressive and anxious symptoms (Hospital Anxiety and Depression Scale), demoralisation (Spanish version of the Demoralisation Scale), perceived loss of dignity (Patient Dignity Inventory) and WTD (Assessing Frequency and Extent of Desire to Die) were collected. The analysis used univariate and multivariate logistic regression

Results The prevalence of WTD in the sample was $18 \%$, with 8 out of 36 patients reporting HDI. The independent factors predictive of WTD were (1) knowledge of approximate prognosis $(\mathrm{OR}=4.78 ; 95 \% \mathrm{Cl}$ 1.20 to $10.8 ; p=0.001$ ); (2) symptom burden $(\mathrm{OR}=1.05 ; 95 \% \mathrm{Cl} 1.00$ to $1.09 ; p=0.038)$; and (3) the Demoralisation Scale subsection 'lack of meaning and purpose in life' (OR=1.61; 95\% Cl 1.30 to $1.99 ; p=0.000$ ). An independent predictive factor for HDI was the Demoralisation Scale subsection 'patients' distress and coping abilities' (OR=1.47; 95\% $\mathrm{Cl} 1.04$ to 2.08; $\mathrm{p}=0.028$ ), while having religious beliefs was a protective factor ( $O R=0.13 ; 95 \% \mathrm{Cl0} .17$ to $0.97 ; \mathrm{p}=0.047$ ).

Conclusions Demoralisation was found to be the only common triggering factor for WTD and $\mathrm{HDI}$, although experiences share certain features. Identification of the predictive factors for WTD and HDI may contribute to their prevention and management.

\section{Key messages}

What was already known?

- The wish to die (WTD) is a complex and dynamic experience influenced by anxiety, depression and perceived loss of dignity.

- Existential distress may influence the experience of WTD and the intention to hasten death.

- Not all patients with WTD have hastening death intention (HDI) and triggering factors may differ.

What are the new findings?

- This study identifies the salience of demoralisation, distress and ineffective coping strategies and the lack of purpose and meaninglessness in patients presenting with WTD and HDI.

- This study identifies the predictive factors for patients expressing HDI.

What is their significance?

- These findings can help guide the development of goals of care for patients with WTD and prevent its occurrence.

- Awareness of the factors that can trigger HDI will assist identification of affected patients and guide their goals of care.

\section{BACKGROUND}

The wish to die (WTD) is common in patients with advanced illness. ${ }^{1-3}$ Between $11 \%$ and $55 \%$ of patients have sporadic WTD $^{1-3}$ while 3\%-20\% have more persistent thoughts. ${ }^{1-3}$

The scientific literature has described different experiences of WTD, ${ }^{4}$ referring to them with varying terminologies such as 'desire to die' or 'wish to hasten death', with no differentiation or consideration of the term's nuances. ${ }^{14}$ A terminological consensus process concluded that the phenomenon should be called 'wish to hasten death'. ${ }^{5}$ However, it is common knowledge that all WTD experiences do 
not include hastening death intention (HDI), although these are embedded in WTD. ${ }^{2}$ Thus, this study follows a recent terminological analysis of the issue, referring to the global phenomenon that includes both sporadic or persistent experiences of WTD and explicitly noting when patients expressed HDI, both as real plans and as passing thoughts. ${ }^{1}$

Research has associated the experience of WTD with different factors, ${ }^{4}$ namely physical (ie, pain, dyspnoea, tiredness), ${ }^{2}{ }^{3}$ psychoemotional (ie, depression, anxiety), ${ }^{26-9}$ existential spiritual (ie, existential suffering, perceived loss of dignity) ${ }^{2}$ and social (ie, feeling that one is a burden). ${ }^{9}$

Health professionals often shy away from exploring and discussing WTD with patients. ${ }^{10}$ A superficial understanding of the phenomenon risks medicalising the situation rather than developing appropriate goals of care or taking preventive measures. ${ }^{10}$

Although WTD should be understood within the sociocultural context of the individual experiencing it, ${ }^{11}$ there has been little research on the topic in Spain. ${ }^{6812}$ Moreover, as WTD does not always include HDI, it could be hypothesised that HDI is associated with specific factors. There has been no research on why some patients with WTD present with HDI, while others do not.

The aim of this study is to identify the predictive factors for WTD and HDI in a Spanish population.

\section{METHODS}

We analysed a cross-sectional study of 201 patients with advanced illness from all over Spain admitted for palliative care in two different hospitals in Navarra between January 2018 and November 2018. More than $64 \%$ of the patients were from different regions. ${ }^{1}$ Patients who met the following criteria were included: (1) with advanced illness (progressive and irreversible disease); (2) expecting death in a maximum period of 1 year according to the referring physician (negative answer to a 'surprise question'); (3) awareness of the life-limiting nature of the disease; (4) ability to conduct a fluent conversation in Spanish; and (5) with cognitive capacity.

Collection of sociodemographic and clinical data (online supplemental file A) preceded two face-to-face clinical encounters with participants to gather information about their experiences of WTD and HDI (within 48-96 hours). The semistructured interviews followed the 'Assessing Frequency and Extent of Desire to Die' $(\mathrm{AFEDD})^{13}$ guideline (online supplemental file B), which explores WTD through five possible answers to direct questions about the existence or frequency of WTD ('No', 'Almost never', 'Sometimes', 'Not daily, but almost every day' and 'Daily'). Another question explores the presence of HDI among those presenting with WTD: 'Just thought about it (about the WTD but not about HDI)', 'Have talked with someone about it (about the WTD but not about HDI)', 'I have thought about ending life, but never would do it (the patient though about HDI)', and 'Yes, there is a plan (the patient has a HDI)'.

Data related to symptom burden (Edmonton Symptom Assessment System-Revised, ESAS-r), ${ }^{14}$ depressive and anxious symptoms (Hospital Anxiety and Depression Scale, HADS), ${ }^{15}$ perceived loss of dignity (Patient Dignity Inventory, PDI) ${ }^{16}$ and demoralisation (Spanish version of the Demoralisation Scale, DS-II (es), with two subscales: (1) meaning and purpose in life and (2) distress and coping strategies) were collected. ${ }^{17}$ The latter refers to the patient's ability to cope with the illness trajectory. These variables have been considered triggering factors for WTD in previous studies. ${ }^{268}$

\section{Data analysis}

Logistic regression was used to analyse the relationship between WTD and HDI with the following research variables: sociodemographics, and physical, emotional and existential concerns. Logistic regression took place when responses (in this cases categories) were known in advance and the classification model was fed by them. Results from the multivariate regression model will be highlighted.

The AFEDD guideline measures two distinct but interrelated experiences: WTD and HDI. In order to study the distinguishing factors for each, data regarding WTD and HDI were analysed independently.

The logistic regression analysis of WTD included the entire study population $(\mathrm{N}=201)$ and assigned response labels according to the significant presence or absence of WTD. Patients experiencing WTD 'sometimes', 'not daily, but almost every day' or 'daily' were included in the sample of patients with WTD.

To distinguish the factors associated with HDI, we considered only the population with WTD $(n=36)$. This included patients who had never thought about hastening death $(n=28)$ and also those who answered 'I have thought about ending life, but never would do it' $(n=5)$ or 'Yes, there is a plan' $(n=3)$. The last two groups of patients were included in the HDI group. They were compared against those who have never thought about hastening death.

STATA V.15 was used for descriptive and statistical analyses. Results with a $\mathrm{p}$ value $<0.05$ were considered significant.

\section{RESULTS}

The prevalence of WTD in the overall sample was $18 \%$ (36 of 201), with HDI identified in 8 (22\%) patients of the subsample. Of the whole sample $(\mathrm{N}=201), 46 \%$ were female, with a mean age of 67. Most participants claimed to have religious beliefs $(86 \%)$, a national norm, and almost all knew their diagnosis (97\%). The Karnofsky score for $76 \%$ of the patients was between 50 and 70 . Of the patients, $21 \%$ had moderate to severe anxiety, while $26 \%$ presented with severe depression. 


\section{Table 1 Predictive factors for wishing to die and hastening death intention}

The wish to die and clinical factors $(\mathrm{N}=201)$

\begin{tabular}{|c|c|c|c|c|c|}
\hline \multirow[b]{2}{*}{ Variable } & \multirow[b]{2}{*}{ Response options } & \multicolumn{3}{|c|}{ Multivariate logistic regression } & \multirow[b]{2}{*}{ P value* } \\
\hline & & OR & $95 \% \mathrm{Cl}$ & SE & \\
\hline \multicolumn{6}{|c|}{ The wish to die and clinical factors ( $\mathrm{N}=201)$} \\
\hline \multirow[t]{2}{*}{ Information about the diseaset } & Diagnostic but not prognostic & 1.00 & 1.20 to 10.8 & 2.26 & $0.001^{*}$ \\
\hline & Diagnostic and prognostic & 4.78 & & & \\
\hline \multirow[t]{2}{*}{ Depression history } & No & 1.00 & 1.42 to 9.13 & 1.69 & 0.232 \\
\hline & Yes & 2.35 & & & \\
\hline \multirow[t]{2}{*}{ Anxiety history } & No & 1.00 & 1.15 to 10.4 & 2.41 & 0.258 \\
\hline & Yes & 2.72 & & & \\
\hline \multirow[t]{2}{*}{ Receiving specialised palliative careł } & No & 1.00 & 1.09 to 7.07 & 0.85 & 0.308 \\
\hline & Yes & 1.68 & & & \\
\hline Karnofsky performance status & $0-100$ & 0.98 & 0.93 to 0.99 & 0.02 & 0.155 \\
\hline
\end{tabular}

The wish to die and patients' systematic evaluations ( $\mathrm{N}=201)$

\begin{tabular}{llllll}
\hline & & \multicolumn{3}{l}{ Multivariate logistic regression } \\
\cline { 3 - 5 } Variable & Evaluation tool (score) & OR & $95 \% \mathrm{Cl}$ & SE & P value* \\
\hline Symptom burden & ESAS-r (0-100) & 1.05 & 1.00 to 1.09 & 0.02 & $0.038^{*}$ \\
Coping abilities§ & DS-II subscale (0-16) & 0.84 & 0.66 to 1.06 & 0.10 & 0.141 \\
Meaning in life§ & DS-II subscale (0-16) & 1.61 & 1.30 to 1.99 & 0.17 & $0.000^{*}$ \\
Depressive and anxious symptoms & HADS (0-42) & 1.01 & 0.94 to 1.09 & 0.04 & 0.773 \\
Self-perceived dignity & PDI (25-125) & 0.99 & 0.95 to 1.04 & 0.02 & 0.673 \\
\hline
\end{tabular}

Hastening death intention and patients' systematic evaluations $(n=36)$

\begin{tabular}{llllll}
\hline & & \multicolumn{3}{c}{ Multivariate logistic regression } \\
\cline { 3 - 5 } Variable & Evaluation tool (score) & OR & $95 \% \mathrm{Cl}$ & SE & P value* \\
\hline Symptom burden & ESAS-r (0-100) & 1.09 & 0.99 to 1.20 & 0.05 & 0.067 \\
Coping abilities & DS-II (0-16) & 1.47 & 1.04 to 2.08 & 0.26 & $0.028^{*}$ \\
\hline
\end{tabular}

*Statistical significance at $p<0.05$.

tInformation about the disease: information that patients were given referring to the diagnosis and prognosis of the disease.

$\ddagger$ Patients receiving specialised palliative care due to their complex needs.

$\S D S-I I$ (es) has two subscales: (1) meaning and purpose in life and (2) distress and coping abilities.

DS-II (es), Spanish version of the Demoralisation Scale; ESAS-r, Edmonton Symptom Assessment System-Revised; HADS, Hospital Anxiety and Depression

Scale; PDI, Patient Dignity Inventory.

About $25 \%$ of the patients were demoralised (online supplemental file A).

\section{Predictive factors for WTD}

The multivariate study found that awareness of both diagnosis and prognosis was significantly predictive of WTD (OR 4.78; 95\% CI 1.20 to 10.8) (table 1), while sociodemographic characteristics were not (online supplemental file C).

Systematic evaluations of patients using multivariate analysis identified high symptom burden (ESAS-r) (OR 1.05; 95\% CI 1.00 to 1.09) and high scores on the 'meaning and purpose' demoralisation subscale (DS-II) (OR 1.61; 95\% CI 1.30 to 1.99) as independent predictive factors. The multivariate analysis considered additional factors such as depressive and anxious symptoms (HADS) and perceived loss of dignity (PDI) and distress and coping strategies (DS-II) (table 1). Although these factors have been suggested as a significant result of the univariate analysis, they had no independent predictive power.

\section{Predictive factors for HDI}

Religious beliefs were the only sociodemographic and clinical factor associated with HDI (OR 0.13; 95\% CI 0.17 to 0.97 ), with these being protective factors (online supplemental file D).

The initial univariate analysis of the factors derived from the systematic evaluation of the patients identified (1) symptom burden (ESAS-r), (2) 'distress and coping strategies' demoralisation subscale, (3) 'meaning and purpose' demoralisation subscale, and (4) depressive and anxious symptoms (HADS) as potential predictive factors. These four were included in the first model subjected to multivariate analysis, where symptomatic burden and 'distress and coping strategies' demoralisation subscale showed near significance $(p=0.128$ and $p=0.096$, respectively). The second multivariate 
analysis with a model of only these two factors found independent predictive value for the 'distress and coping strategies' subscale (OR 1.47; 95\% CI 1.04 to 2.08) (table 1).

\section{DISCUSSION}

\section{Clinical predictive factors}

Demoralisation was a key trigger of WTD experience among the patients studied. Demoralisation measured with the DS-II (es) consists of two components: 'meaning and purpose' and 'distress and coping strategies'. The first has been extensively studied. Morita $e t$ $a l^{18}$ presented lack of existential meaning as one of the factors underlying WTD, an association confirmed by recent quantitative international studies. ${ }^{7}$ Freeman et $a l^{19}$ in a multivariate analysis observed a higher probability of WTD (OR 2.68) when patients experience existential distress. Qualitative studies on WTD also report an association between existential distress and general demoralisation. ${ }^{20}$

We identified HDI triggers that explain why some patients with WTD present with HDI while others do not by studying HDI independent of the more general experience of WTD. No studies we know of have addressed the distinction. Despite the limitations of having low prevalence in a sample of 201 patients, we observed that patients with higher levels of distress and lower perception of effective coping strategies were more likely to present with HDI. Our literature review revealed that this is the first time distress and perceived lack of coping strategies have been considered as HDI triggers.

Symptom burden is also a key trigger of WTD and is close to statistical significance in HDI. In WTD, this relationship has been described in terms of pain or symptom burden as a whole, as well as concrete symptoms such as dry mouth, ${ }^{21}$ tiredness, ${ }^{3}{ }^{19}$ drowsiness ${ }^{319}$ and incontinence. ${ }^{19}$

\section{Sociocultural factors}

Although we have not found a significant association between religious beliefs and WTD, it is observed that weaker beliefs made HDI more likely. Religious beliefs, possibly due to their association with a transcendent perspective, were identified as a protective factor for HDI.

Health professionals in Mediterranean cultures often avoid communicating with patients about disease progression and prognosis. ${ }^{6}$ Our results were confirmed by other studies that have reported uncertainty and hopelessness in patients with cancer who knew their condition was terminal. These studies suggest a WTD trigger ${ }^{920}$ or even a higher number of euthanasia requests. ${ }^{21}$ Providing patients with adequate care ${ }^{22}$ during the disease process and offering appropriate coping strategies when giving 'bad news' may be protective factors. ${ }^{23}$
These findings can guide interventions for patients presenting with WTD and assist in its identification and prevention. The quality of patient communications regarding prognosis should be considered along with symptom burden and demoralisation. ${ }^{23}$ Clarifying triggering factors for HDI could assist in the identification of at-risk patients, as well as in the development of appropriate interventions and goals of care. Early follow-up by palliative care teams may assist in the development of patient coping strategies. ${ }^{24}$

Exclusion of patients in their very last days of life and those with uncontrolled depressive and anxious symptoms may be a limitation. We recommend future research that explores WTD and HDI triggers separately due to this study's limited number of analysed WTD experiences out of the 201 patients.

\section{CONCLUSIONS}

Distress and ineffective coping strategies are two HDI triggers in patients with WTD. Lack of meaning and purpose in life and patient symptom burden underlie WTD. Professionals should consider these factors when identifying patients with WTD or HDI and developing prevention strategies and goals of care.

\section{Twitter Maria Arantzamendi @marantzamendi}

Acknowledgements Thanks to the multidisciplinary teams in our two partner hospitals who collaborated with the research team.

Collaborators Katherine Pettus.

Contributors $\mathrm{AB}, \mathrm{MA}$ and $\mathrm{CC}$ designed the study. $\mathrm{AB}$ was responsible for the data collection, supported by MM, YS and ML. AB and JL-F were involved in the data analysis and interpretation, with support from MA and CC. The final manuscript was written by $\mathrm{AB}, \mathrm{MA}$ and $\mathrm{CC}$ with contributions from the other authors. All the authors read and approved the submitted version.

Funding This study received funding from Project PI18/01703, integrated into the Plan Estatal de I+D+I 2013-2016 and cofinanced by the ISCIII-Subdirección General de Evaluación y Fomento de la Investigación and the Fondo Europeo de Desarrollo Regional (FEDER).

Competing interests None declared.

Patient consent for publication Not required.

Ethics approval The Clinical Ethical Research Committee of the Clínica Universitaria de Navarra approved the study (no 2017.092).

Provenance and peer review Not commissioned; externally peer reviewed.

Open access This is an open access article distributed in accordance with the Creative Commons Attribution Non Commercial (CC BY-NC 4.0) license, which permits others to distribute, remix, adapt, build upon this work noncommercially, and license their derivative works on different terms, provided the original work is properly cited, appropriate credit is given, any changes made indicated, and the use is noncommercial. See: http://creativecommons.org/licenses/by-nc/4. $0 /$.

\section{ORCID iDs}

Alazne Belar http://orcid.org/0000-0002-4831-5218

Carlos Centeno http://orcid.org/0000-0003-3395-7039 


\section{REFERENCES}

1 Belar A, Arantzamendi M, Santesteban Y, et al. Cross-sectional survey of the wish to die among palliative patients in Spain: one phenomenon, different experiences. BMJ Support Palliat Care 2021;11:156-62.

2 Wilson KG, Dalgleish TL, Chochinov HM, et al. Mental disorders and the desire for death in patients receiving palliative care for cancer. BMJ Support Palliat Care 2016;6:170-7.

3 Julião M, Nunes B, Barbosa A. Prevalence and factors associated with demoralization syndrome in patients with advanced disease: results from a cross-sectional Portuguese study. Palliat Support Care 2016;14:468-73.

4 Monforte-Royo C, Villavicencio-Chávez C, Tomás-Sábado J, et al. The wish to hasten death: a review of clinical studies. Psychooncology 2011;20:795-804.

5 Balaguer A, Monforte-Royo C, Porta-Sales J, et al. An international consensus definition of the wish to hasten death and its related factors. PLoS One 2016;11:e0146184.

6 Villavicencio-Chávez C, Monforte-Royo C, Tomás-Sábado $\mathrm{J}$, et al. Physical and psychological factors and the wish to hasten death in advanced cancer patients. Psychooncology 2014;23:1125-32.

7 Robinson S, Kissane DW, Brooker J, et al. The relationship between poor quality of life and desire to hasten death: a multiple mediation model examining the contributions of depression, demoralization, loss of control, and low self-worth. J Pain Symptom Manage 2017;53:243-9.

8 Guerrero-Torrelles M, Monforte-Royo C, Tomás-Sábado $\mathrm{J}$, et al. Meaning in life as a mediator between physical impairment and the wish to hasten death in patients with advanced cancer. J Pain Symptom Manage 2017;54:826-34.

9 Ohnsorge K, Rehmann-Sutter C, Streeck N, et al. Wishes to die at the end of life and subjective experience of four different typical dying trajectories. A qualitative interview study. PLoS One 2019;14:e0210784:26.

10 Ohnsorge K, Gudat H, Rehmann-Sutter C. Intentions in wishes to die: analysis and a typology--a report of 30 qualitative case studies of terminally ill cancer patients in palliative care. Psychooncology 2014;23:1021-6.

11 Rodríguez-Prat A, van Leeuwen E. Assumptions and moral understanding of the wish to hasten death: a philosophical review of qualitative studies. Med Heal Care Philos 2017;0:1-13.

12 Monforte-Royo C, Crespo I, Rodríguez-Prat A, et al. The role of perceived dignity and control in the wish to hasten death among advanced cancer patients: a mediation model. Psychooncology 2018;27:2840-6.

13 Porta-Sales J, Crespo I, Monforte-Royo C, et al. The clinical evaluation of the wish to hasten death is not upsetting for advanced cancer patients: a cross-sectional study. Palliat Med 2019;33:570-7.

14 Bruera E, Kuehn N, Miller MJ, et al. The edmonton symptom assessment system (ESAs): a simple method for the assessment of palliative care patients. J Palliat Care 1991;7:6-9.

15 Herrero MJ, Blanch J, Peri JM, et al. A validation study of the hospital anxiety and depression scale (HADS) in a Spanish population. Gen Hosp Psychiatry 2003;25:277-83.

16 Chochinov HM, Hassard T, McClement S, et al. The patient dignity inventory: a novel way of measuring dignityrelated distress in palliative care. J Pain Symptom Manage 2008;36:559-71.

17 Belar A, Arantzamendi M, Rodríguez-Núñez A, et al. Multicenter study of the psychometric properties of the new demoralization scale (DS-II) in spanish-speaking advanced cancer patients. J Pain Symptom Manage 2019;57:627-34.

18 Morita T, Sakaguchi Y, Hirai K, et al. Desire for death and requests to hasten death of Japanese terminally ill cancer patients receiving specialized inpatient palliative care. J Pain Symptom Manage 2004;27:44-52.

19 Freeman S, Smith TF, Neufeld E, et al. The wish to die among palliative home care clients in ontario, Canada: a crosssectional study. BMC Palliat Care 2016;15:24.

20 Rodríguez-Prat A, Balaguer A, Booth A, et al. Understanding patients' experiences of the wish to hasten death: an updated and expanded systematic review and meta-ethnography. BMJ Open 2017;7:e016659.

21 Güell E, Ramos A, Zertuche T, et al. Verbalized desire for death or euthanasia in advanced cancer patients receiving palliative care. Palliat Support Care 2015;13:295-303.

22 Pestinger M, Stiel S, Elsner F, et al. The desire to hasten death: using grounded theory for a better understanding "when perception of time tends to be a slippery slope". Palliat Med 2015;29:711-9.

23 van der Velden NCA, Meijers MC, Han PKJ, et al. The effect of prognostic communication on patient outcomes in palliative cancer care: a systematic review. Curr Treat Options Oncol 2020;21:40.

24 Zimmermann C, Swami N, Krzyzanowska M, et al. Early palliative care for patients with advanced cancer: a clusterrandomised controlled trial. Lancet 2014;383:1721-30. 